Int. J. Dev. Biol. 57: 659-665 (2013)

doi: $10.1387 / \mathrm{ijdb} .130230 \mathrm{cr}$

\title{
Transformation of the mitochondrial genome
}

\author{
VÉRONIQUE LAROSA and CLAIRE REMACLE* \\ Genetics of Microorganisms, Department of Life Sciences, Institute of Botany, University of Liege, Liege, Belgium
}

\begin{abstract}
Although mitochondrial transformation is highly desirable in mammals and plants, it is only possible in two unicellular organisms, the budding yeast Saccharomyces cerevisiae and the unicellular green alga Chlamydomonas reinhardtii. Here, we give an overview of the attempts made to transform mitochondria of mammals and plants and the possible reasons for their failure. This review briefly describes the mitochondrial transformation principles in yeast and describes in more detail the transformation and its applications in Chlamydomonas.
\end{abstract}

KEY WORDS: mitochondria, transformation, Chlamydomonas, respiration, mutation

\section{Introduction}

Mitochondria are the main sites where the biological energy is generated in eukaryotes. As semiautonomous organelles, they possess their own genome, the mitochondrial DNA (mtDNA), that differs in form and size among the various organisms and occurs in multiple copies, varying from a few dozen up to several thousand copies per cell. The mtDNAcan form circular molecules in mammals (Boore, 1999) and in some plants, such as bryophytes (liverworts, hornworts and mosses) (Terasawa et al., 2007). In contrast, some organisms, such as the unicellular green alga Chlamydomonas reinhardtii, show linear mtDNAs that end with defined terminal structures, called mitochondrial telomeres (Vahrenholz etal., 1993).

Concerning the mtDNA size, the genomes are generally small, such as in humans in which the mtDNA is a circular double-stranded molecule of $16 \mathrm{~kb}$ (Anderson et al., 1981), whereas those of seed plants are much larger, ranging from $221 \mathrm{~kb}$ for the smallest mitochondrial genome sequenced to date (Handa, 2003) to more than 2,000 kb for the Cucurbitaceae or Silene families (Ward et al., 1981; Sloan et al., 2012). The size enlargement does not reflect an increase in the gene content, but rather additional noncoding sequences, such as introns, DNA repeat motifs, and inserted nuclear and chloroplast fragments (Knoop, 2004). For example, the mtDNA of Arabidopsis Thaliana is 22-fold larger than that of Homo sapiens, but its coding capacity is only 2.5 -fold stronger (Unseld et al., 1997). In addition, seed plants possess a complex pool of frequently recombining molecules, of which the stoichiometry is controlled by nuclear genes (Arrieta-Montiel et al., 2009).

Even though the mtDNA varies in form and shape, as far as we know it plays the same fundamental role in all eukaryotes and it encodes a limited number of ribosomal ( $r$ )RNAs, transfer (t)RNAs, and proteins essential for respiration (Gray, 1999).

\section{Mitochondrial diseases and defects: transformation capacity and incapacity}

\section{Mammals}

In humans, mtDNA mutations are found in subunits of the respiratory chain complexes or in tRNAs and rRNAs (listed at www. mitomap.org) and are known to cause a wide array of clinical disorders related to defects in the energy metabolism. It is generally accepted that 1 on 3,500 to 6,000 individuals harbors mtDNA mutations (Taylor and Turnbull, 2005). There is increasing evidence from mammalian models (Trifunovic et al., 2004) that acquired mtDNA mutations and mitochondrial dysfunctions are involved in ageing and age-related diseases, such as diabetes (Petersen et al., 2003). However, the mtDNA mutations are difficult to analyze for the reasons cited below.

As the mitochondrial genome is present in multiple copies, some mutations can affect all the copies (homoplasmic mutation), whereas others occur only in some of the copies (heteroplasmic mutation). These heteroplasmic mutations can escape detection because the impact of the mutation might be hidden by the wild-type copies. In addition, the mitochondrial genome harbors large numbers of polymorphic base changes without pathogenic significance (DiMauro, 2007). Furthermore, mitochondrial diseases can also arise from nuclear gene disorders, because most proteins involved in the mitochondrial metabolism and all those involved in the mtDNA maintenance are encoded in the nucleus. Therefore, a system is highly needed and desirable that would allow us to study the mutations located in the mitochondrial genome and, hence,

Abbreviations used in this paper: mtDNA, mitochondrial DNA; ; rRNA, ribosomal RNA; tRNA, transfer RNA.

\footnotetext{
*Address correspondence to: Claire Remacle. Boulevard du Rectorat 27, Bâtiment 22, B-4000 Liège, Belgium. Tel. +32-4-366-3812. Fax: +32-4-366-3840.

E-mail: c.remacle@ulg.ac.be
}

Final, author-corrected PDF published online: 16 October 2013.

ISSN: Online 1696-3547, Print 0214-6282 


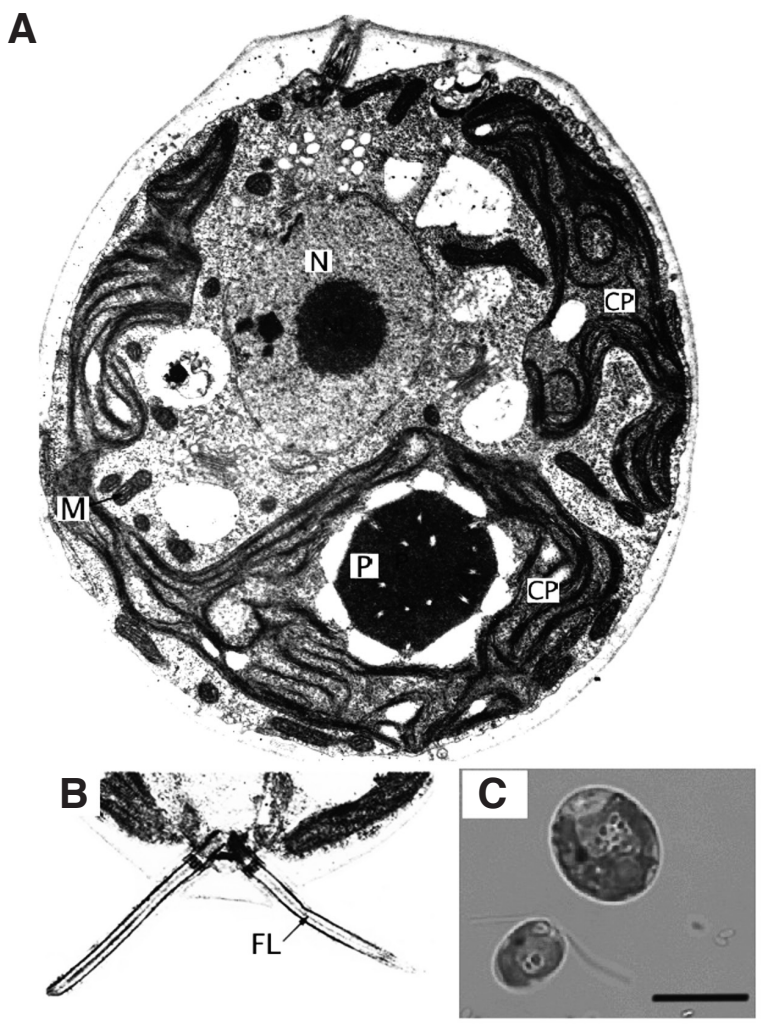

Fig. 1. Microscopic images of $\boldsymbol{C}$. reinhardtii. (A) Electron microscopy. $C P$, chloroplast; $M$, mitochondria; $N$, nucleus; $P$, pyrenoid (site of $\mathrm{CO}_{2}$ fixation). (B) Electron microscopy. FL, flagella. (C) Optical microscopy. The black bar represents $10 \mu \mathrm{m}$.

transform mtDNAs of mammalian cells.

In fact, in mammalian cells, small linear DNA fragments, such as oligonucleotides (Vestweber and Schatz, 1989) or double-stranded DNA (Seibel et al., 1995; Koulintchenko et al., 2006) can be transported into mitochondria (Chinnery et al., 1999; Geromel et al., 2001; Flierl et al., 2003). Much enlarged plasmid DNA molecules have been introduced also into isolated mammalian mitochondria by electroporation (Collombet et al., 1997), but the electroporation conditions used in these procedures appear to damage irreparably the mitochondria, thus preventing their reincorporation into the mammalian cells (Yoon and Koob, 2005). Introduction of an exogenous DNA into the mitochondria of human cells by means of a process called 'protofection', a system involving bacteria-tomitochondria conjugation (Yoon and Koob, 2005), had been tried, but was inconclusive. Some successes were obtained by transfer of in vitro mitochondria from a patient, suffering from mitochondrial pathology, into cultured mtDNA-less human cells (Chomyn et al., 1991; Hayashi et al., 1991). Moreover, viable mitochondria, isolated from human somatic cells, were microinjected in vitroin mouse (Mus musculus) cells, but these analyses were not followed up (Irwin et al., 1999; Takeda et al., 2005). However, a promising approach is the use of adeno-associated viruses to express human mitochondrial genes in mice (Yu et al., 2012a). By means of this technique, a human mitochondrial mutation responsible for vision loss, the Leber Hereditary Optic Neuropathy, has been introduced into the ocular mitochondria of mice (Yu et al., 2012b) and expression and translation of the construction has been detected. Unfortunately, the construction did not seem to be integrated into the mitochondrial genome and, thus far, in vivo direct engineering of the mtDNA in mammalian mitochondria is still impossible.

\section{Plants}

Regarding plants, mitochondrial disorders have been identified also in subunits of the respiratory-chain complexes, leading to visible phenotypes, such as the cytoplasmic male sterility in tobacco (Nicotiana sylvestris) (Gutierres et al., 1997) or the nonchromosomal stripe phenotype in maize (Zea mays) (Karpova and Newton, 1999). Although such genotypes might represent good candidates for mitochondrial transformation, it is still impossible to stably transform plant mitochondria. Like in mammals, in vitro import of DNA, electroporation of isolated mitochondria with DNA/ RNA, and in vivotransformation experiments have been performed, but not successful (reviewed in Remacle et al., 2012). The reasons for the failure are probably multiple and could be linked to the instability of the plant mitochondrial genomes and to the lack of strong selection markers that can be maintained throughout the development of the adult plant after the zygote formation. Indeed, in higher plants, subgenomes are found and their presence is due to high-frequency intermolecular and intramolecular recombinations on large repeated sequences. When these repeated sequences are in direct orientation, they allow the genome to be subdivided into a collection of molecules, each containing only a portion of the genetic information. These molecules of plant mitochondrial DNA can vary in copy number over time, a process called substoichiometric shifting (Small et al., 1987; Janska et al., 1998; Abdelnoor et al., 2003) that leads to heteroplasmic complexity (Woloszynska, 2010). Silencing of genes that control such shifting, such as the DNA mismatch repair protein MSH1 that is homologous to mutator protein MutS in Escherichia coli (Abdelnoor et al., 2003), might be a good approach to solve the problem of plant transformation.

Nevertheless, it is worth mentioning that manipulation of mitochondrial expression might be possible via the antisense strategy. Indeed, knockdown of the expression of the mitochondrial subunit 9 ATP-ase gene ATP9 of Arabidopsis plants has been demonstrated via stable transformation of the nuclear genome. To this end, a chimeric catalytic RNA was constructed that consisted of a specifically designed trans-cleaving hammerhead ribozyme and a tRNAmimic targeting the construction to the mitochondria, because many cytosolic tRNAs are imported to the mitochondria to ensure proper mitochondrial translation in seed plants (Val et al., 2011).

In conclusion, even though technologies to study mitochondria, such as isolation of mitochondria, biochemical and microscopic analyses, and genome sequencing have evolved and been improved, in vivo and stable mitochondrial transformation is still feasible in two unicellular organisms only, namely the budding yeast Saccharomyces cerevisiae (Fox et al., 1988; Johnston et al., 1988) and the green alga Chlamydomonas reinhardtii (Remacle et al., 2006). High-efficiency transformation methods relying on biolistic delivery have been developed, in which respiratory-deficient mutants serve as recipient strains for mitochondrial transformation.

\section{Mitochondrial transformation of Saccharomyces cere- visiae}

In S. cerevisiae, the mitochondrial transformation process is possible thanks to the fact that DNA sequences can be delivered 
into the yeast mitochondria by microprojectile bombardment (biolistic transformation) and be incorporated successively into the mtDNA by the highly active homologous recombination machinery present in the organelle (Bonnefoy and Fox, 2007). As recipient strains, S. cerevisiae cells that lack part (rho-) or all (rho0) of the mtDNA are routinely used for transformation. In fact, rho- mtDNAs replicate independently of the protein synthesis and do not require a specific replication origin sequence. These strains can be transformed with bacterial plasmid DNAs that subsequently propagate defined mtDNAs as 'synthetic' rho- molecules (Fox et al., 1988) or can be transformed also with linear DNA molecules obtained either from plasmid clones or polymerase chain reaction (PCR) amplification (Bonnefoy and Fox, 2002). Alternatively, when a mutated DNA sequence provides a function that can be selected phenotypically, direct transformation of rho+ strains bearing deletions in the region of interest can be used to integrate mutations into the mtDNA (Bonnefoy and Fox, 2000; Bonnefoy et al., 2001). In yeast, auxotrophic markers that correspond to nuclear genes encoding mitochondria-targeted enzymes are attractive for the development of a selection method. Indeed, expression of the biosynthetic arginine gene $A R G 8$ from the mitochondrial genome allows nuclear arg8 mutants to grow without arginine (Steele et al., 1996). The ARG8 protein is normally imported into mitochondria from the cytoplasm, but also functions when synthesized within the organelle in the mitochondrial transformants. Thus, arginine prototrophy might become a mitochondrial gene expression-dependent phenotype dependent.

\section{Mitochondrial transformation of C. reinhardtii}

\section{Principles}

The second organism in which stable mitochondrial transformation is feasible is $C$. reinhardtii, also called green yeast (Fig. 1 ). This two-flagellar microalga is $10 \mu \mathrm{m}$ long and consists of a haploid nuclear genome of $120 \mathrm{Mb}$ (Merchant et al., 2007), a very large horseshoe-shaped chloroplast containing circular DNA molecules of $220 \mathrm{~kb}$ (Maul et al., 2002), and small mitochondria containing linear DNA molecules of $15.8 \mathrm{~kb}$. These molecules are terminated by telomeres made of inverted repeats of approximately
500 bp (Vahrenholz et al., 1993). Thirteen genes are present and encode five subunits of the NADH:ubiquinone oxidoreductase or complex I ( $n d 1, n d 2, n d 4, n d 5$, and $n d 6)$, apocytochrome $b$ of the $b c_{1}$ complex or complex III (cob), subunit 1 of cytochrome $c$ oxidase or complex IV (cox1), a reverse transcriptase-like protein (rth), three tRNAs (trnW, trnQ, and trnM), and the rRNAs (Fig. 2A). The rRNA genes are discontinuous and split into mini-sequences that encode four small subunit $(S)$ and eight large subunit $(L)$ rRNA modules, interspersed with one another and with protein and tRNA genes. The small rRNA segments of the two ribosomal subunits are believed to interact through an extensive intermolecular pairing to form conventional rRNA molecules (Boer and Gray, 1988).

The mitochondrial genome is a multicopy system of approximately 50-100 copies organized into 20-30 nucleoids (Hiramatsu et al., 2006). The nucleoids and the mitochondria seem extremely dynamic and undergo changes in size and shape during the cell cycle (Hiramatsu et al., 2006).

The first successful mitochondrial transformation in Chlamydomonas was a dark uniparental minus (dum1) mutant (Fig. 2B) in which the left telomere and cobgene ( $1.5 \mathrm{~kb}$ deletion) were deleted. Such a respiratory mutant, isolated after random mutagenesis with acriflavine (Remacle et al., 2001), has lost the capacity to grow under heterotrophic conditions, i.e. in the dark, with acetate as carbon source, because it lacks the cytochrome pathway of respiration (Fig. 2C). In this first round of transformation experiments, the respiratory competence was restored in dum 1 by means of a biolistic device and partially purified mtDNA from C. reinhardtii or C. smithii (Randolph-Anderson et al., 1993). Later, biolistics was again used successfully to transform the same recipient strain with purified mtDNA or cloned mtDNA fragments (Yamasaki et al., 2005). In both cases, the wild-type mitochondrial sequence of the transformed DNA replaced the deleted genome in the transformants selected under heterotrophic conditions (dark+acetate) and the transformation efficiency was low (0.4-3 transformants/ $\mu$ gNA).

Subsequently, the biolistic transformation was optimized by using cloned mtDNA or PCR fragments as transforming molecules (Remacle et al., 2006) and a deletion mutant carrying a 1.2-kb deletion, including the left telomere and part of the cob gene (dum11) (Fig. 2B). This mutant also lacks the cytochrome pathway
A

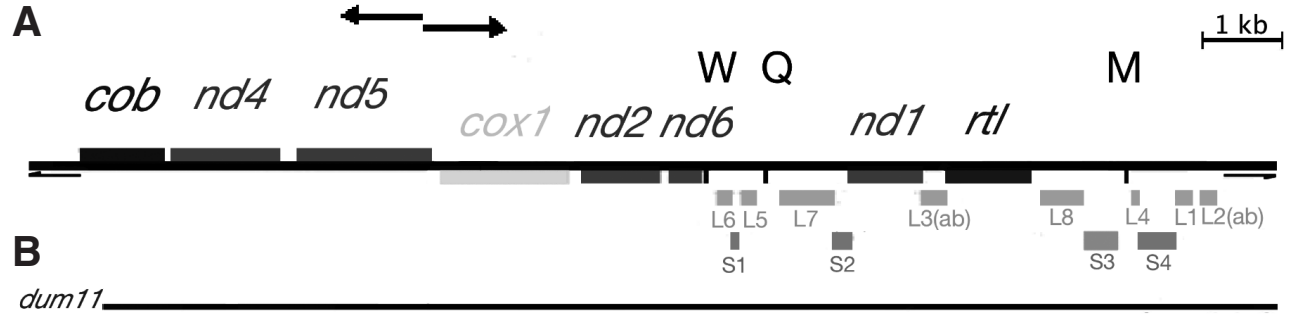

dum11.

dum1.

dum22

donor DNA

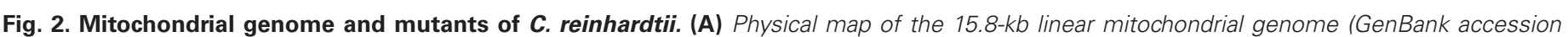

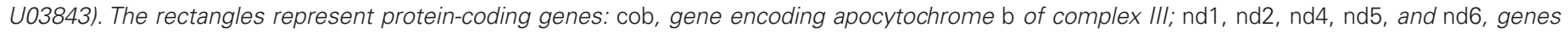

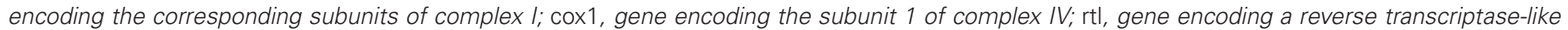

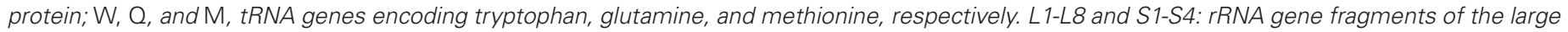

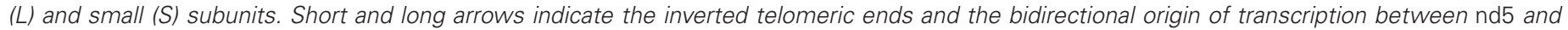

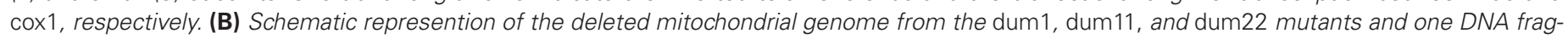

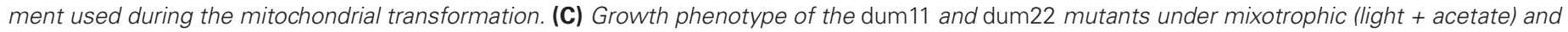
heterotrophic (dark + acetate) conditions. 
of respiration and could not grow under heterotrophic conditions (Fig. 2C). Mitochondrial transformants obtained from dum11 could be rescued after selection in the dark with a mtDNA fragment covering the deletion and the cob/nd4/nd5 genes as donor DNA (Fig. 2B). Homologous recombination occurred between the introduced DNA and the endogenous mitochondrial genome and homologous sequences as short as 28 nucleotides could recombine (Remacle et al., 2006). The mitochondrial transformants were homoplasmic for the $15.8 \mathrm{~kb}$ wild-type genome. Moreover, high transformation efficiency was achieved (100-250 transformants/ $\mu \mathrm{g}$ DNA) and the best results were obtained with linearized plasmid DNA.

Using the strategy described above, we were able to introduce nondeleterious mutations and also loss-of-function molecular lesions into the mitochondrial genome. Myxothiazol-resistant transformants were generated by introducing the mud2 mutation at codon 129 that is present in the cob gene of the strains displaying myxothiazol resistance (Remacle et al., 2006). Similarly, an in-frame deletion of 23 codons was reconstructed in the nd4 gene (Remacle et al., 2006). During selection in the dark, recombination events resulted in cobgene cointegration and $n d 4$ deletion in some molecules of the mitochondrial genome, despite the negative effects of the nd4 mutation on the complex-I assembly and activity and on the total cellular respiration (Remacle et al., 2006). After a 2-month selection in the dark, heteroplasmy could still be detected in some transformants, suggesting that the segregation process of the mitochondrial molecules was extremely slow. To circumvent the heteroplasmy problem, we used a mutant with a deletion extending up to nd4 (dum22) (Fig. 2B) (Remacle et al., 2001) to force mutations to be inserted into $n d 4$ by recombination. The dum22 mutant depends totally on glycolysis and chloroplasts for ATP formation, because it lacks the three phosphorylating enzymes of the respiratory chain (complexes I, III, and IV). This mutant has proven to be a good recipient strain to isolate homoplasmic nd4 transformants, although the transformation efficiency is very low (1-2 transformants/ug DNA) (see below).

\section{Applications}

These results opened the way to reverse genetics in Chlamydomonas mitochondria. The three recipient strains cited above, dum1, dum 11, and dum22, were efficiently used in transformations (i) to reconstruct a human mitochondrial complex-I mutation in Chlamydomonas, (ii) to elucidate the tRNA import in mitochondria, and (iii) to express transgenes in mitochondria.

\section{Reconstruction of a human mitochondrial complex-I mutation in Chlamydomonas}

As described above, the pathogenicity of a given mitochondrial mutation can be difficult to analyze because the mitochondrial genome harbors large numbers of polymorphic base changes without pathogenic significance (DiMauro, 2007). In addition, mitochondrial mutations are usually found in the heteroplasmic state, by which the biochemical effects of the mutation could be hidden. Human mitochondrial mutations can be reconstructed in the $S$. cerevisiae (Blakely et al., 2005), except for complex-I mutations because it lacks complex I and oxidizes NADH via a monomeric type-II NADH dehydrogenase. As a substitute, bacterial systems have been used to reconstruct human pathogenic mutations (Blakely et al., 2005; Torres-Bacete et al., 2007); however, they are not ideal, because the membrane domain of the eukaryotic complex I is much more complex than the corresponding arm of the bacterial complex I (28 subunits versus 7 subunits). Therefore, we proposed that Chlamydomonas could represent an attractive eukaryotic system to study such mutations (Larosa et al., 2012) because (i) respiratory-deficient mutants are viable and mitochondrial mutations are found in the homoplasmic state (Remacle et al., 2001), (ii) transformation of the mitochondrial genome is feasible (Remacle et al., 2006), and (iii) the Chlamydomonas complex I is close to that of humans (Cardol, 2011). Indeed, of the 42 subunits of the Chlamydomonas complex I, 40 are homologous to those of the human complex I (Cardol, 2011). As an illustration, a Leu ${ }_{157}$ Pro (Fig. $3 A$ ) substitution was introduced into the ND4 subunit of the Chlamydomonas complex I of two different recipient strains (dum11 and dum22) by biolistic transformation. This substitution did not lead to any defective respiratory enzymes when occurring at the heteroplasmic state in a patient presenting chronic progressive external ophthalmoplegia. When present at the homoplasmic state in the alga, the mutation did not prevent the assembly of the 950-kDa whole complex I that conserves nearly all the NADH dehydrogenase activity of the peripheral arm, but the NADH:duroquinone oxidoreductase activity was strongly reduced. Due to its nature, the introduced proline could disturb the organization of the transmembrane domain (Fig. 3B), in which the substitution is found and affects the ubiquinone fixation to the membrane domain. The in vitro defects were correlated in vivo with decreased respiration and growth rates.

\section{Coevolution of mitochondrial tRNA Import and codon usage determines translational efficiency in Chlamydomonas}

The mitochondrial translational machinery of Chlamydomonas strongly depends on cytosolic tRNA import, because only three tRNA genes are encoded by the mitochondrial genome (Fig. 2). Indeed, of the 49 cytosolic tRNA isoacceptors, 34 are found in mitochondria (Vinogradova et al., 2009). In addition, this import is very specific because only necessary cytosolic tRNAs are introduced. The mitochondrial localization extent for each tRNA species is highly

\section{A}

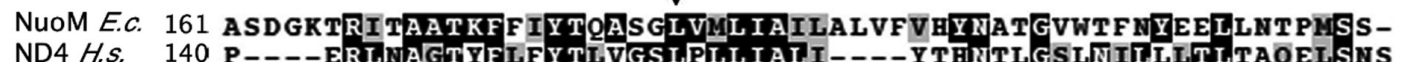
ND4 H.S. 140 P----ERLNAGTYFLF TLVGSLPLL I ALI-- - Y THNTLGSLNILLITLTAQELSNS ND4 C.r. 139 Y----GSLEA AYI IVIY TIA G LVLLPTLF----MIYSECGTTNVLYMTCAYRH---B

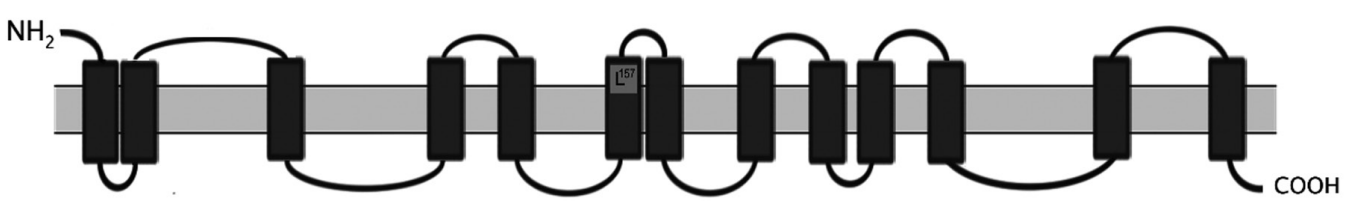

Fig. 3. ND4 subunit topology and alignment. (A) Partial alignment between the Escherichia coli NuoM subunit, humane, and C. reinhardtii ND4 subunit. Arrow marks the leucine (at position 157 in Chlamydomonas) substituted by a proline. (B) Hypothetical model for the folding of the Chlamydomonas ND4 subunit, including 13 putative transmembrane helices. The Leucine $_{157}$ is highlighted in the sixth helix. 
variable: the percentage for most of them ranges from $0.2 \%$ to $26 \%$, whereas three cytosolic tRNAs are nearly exclusively located inside the mitochondria. The correlation of the import efficiency with the mitochondrial codon usage (Vinogradova et al., 2009) led to the hypothesis that the tRNA import might be a dynamic process capable of adaptation to the mitochondrial genome content. By manipulating the Chlamydomonas mitochondrial genome with the two recipient strains dum11 and dum22, we introduced point mutations and found that the codon usage modifications resulted in reduced mitochondrial translation levels and in subsequently decreased respiratory complex levels and activities. These effects were linked to the consequential limitations of the tRNA pools in mitochondria. This observation indicated that the tRNA mitochondrial import cannot be regulated rapidly in response to a novel genetic context and, thus, is seemingly not a dynamic process, but rather suggested that the steady-state levels of imported tRNAs in mitochondria result from a coevolutive adaptation between the tRNA import mechanism and the requirements of the mitochondrial translation machinery (Salinas et al., 2012).

\section{Transgene expression in Chlamydomona mitochondria}

The gene encoding the enhanced green fluorescent protein egfp was inserted between the cob gene and the left terminal repeat, with the dum1 strain as recipient. The egfp gene was successfully expressed in the mitochondria of the transformants, as demonstrated by confocal microscopy and Western blot analyses (Hu et al., 2011). Similarly, the zeomycin resistance conferring gene ble from Streptoalloteichus hindustanus was inserted at the same site and with the same recipient strain. After 2 months of selection in the dark, the ble gene was expressed and the transformants grew on zeomycin. However, the concentrations used were much lower (3-5 $\mu \mathrm{g} / \mathrm{ml}$ ) than those usually reported for algae, yeasts, and mammals $(100 \mu \mathrm{g} / \mathrm{ml})$ (Hu et al., 2012). Nevertheless, the expression of the ble gene in mitochondria could be developed as a resistance marker for transgenic expression of other kinds of recombinant proteins in Chlamydomonas mitochondria.

\section{Perspectives}

Our century tends to study genes and their engineering. Indeed, forward and reverse genetics approaches are currently developed to address a lot of biological questions (Barbieri et al., 2011; Huang et al., 2012; Rahrmann et al., 2013). Moreover, the evolution and the democratization of high-throughput sequencing enriched such a research.

Thus far, genome manipulations can be achieved in all organisms, except for mitochondrial transformation that is still a challenge in multicellular eukaryotes. The complexities of these organisms and the absence of selection criteria are major obstacles that need to be solved.

Concerning the mitochondrial transformation of Chlamydomonas, an obvious limitation is the selection process that requires a 2-month incubation period in the dark before any molecular characterization can be performed. Although the expression of antibiotic resistance genes in the mitochondria is attractive, it is still necessary to apply the dark selection before addition of the antibiotic to the culture (Hu et al., 2011, 2012). Therefore, the development of a more rapid selection using phototrophic growth for the generation of mitochondrial transformants is a high priority.
Currently, we are testing several strategies in our laboratory, such as cotransformation and new recipient strains affected both in chloroplasts and mitochondria to maximize the light dependence of the cellular respiration.

\section{Acknowledgments}

This work was supported by grants from the 'Fonds de la Recherche Fondamentale Collective' (CDR J.0138.13) and 'Fonds spéciaux de I'Université de Liège'. V.L. is a Postdoctoral Researcher of Fonds de la Recherche Scientifique (F.R.S.-FNRS).

\section{References}

ABDELNOOR RV, YULE R, ELOA, CHRISTENSEN AC, MEYER-GAUEN G, MACKENZIE SA (2003). Substoichiometric shifting in the plant mitochondrial genome is influenced by a gene homologous to MutS. Proc NatlAcad SciUSA 100:5968-5973.

ANDERSON S, BANKIER AT, BARRELL BG, DE BRUIJN MHL, COULSON AR, DROUIN J, EPERON IC, NIERLICH DP, ROE BA, SANGER F, SCHREIER PH, SMITH AJH, STADEN R, YOUNG IG (1981). Sequence and organization of the human mitochondrial genome. Nature 290: 457-465.

ARRIETA-MONTIEL MP, SHEDGE V, DAVILA J, CHRISTENSEN AC, MACKENZIE SA (2009). Diversity of the Arabidopsis mitochondrial genome occurs via nuclearcontrolled recombination activity. Genetics 183: 1261-1268.

BARBIERI MR, LAROSA V, NOUET C, SUBRAHMANIAN N, REMACLE C, HAMEL PP (2011). A forward genetic screen identifies mutants deficient for mitochondrial complex I assembly in Chlamydomonas reinhardtii. Genetics 188: 349-358.

BLAKELY EL, MITCHELL AL, FISHER N, MEUNIER B, NIJTMANS LG, SCHAEFER AM, JACKSON MJ, TURNBULL DM, TAYLOR RW (2005). A mitochondrial cytochrome $b$ mutation causing severe respiratory chain enzyme deficiency in humans and yeast. FEBS J 272: 3583-3592.

BOER PH, GRAY MW (1988). Scrambled ribosomal RNA gene pieces in Chlamydomonas reinhardtii mitochondrial DNA. Cell 55: 399-411.

BONNEFOY N, FOX TD (2000). In vivo analysis of mutated initiation codons in the mitochondrial COX2gene of Saccharomyces cerevisiaefused to the reporter gene $A R G 8^{m}$ reveals lack of downstream reinitiation. Mol Gen Genet 262: 1036-1046.

BONNEFOY N, FOX TD (2007). Directed alteration of Saccharomyces cerevisiae mitochondrial DNA by biolistic transformation and homologous recombination. Methods Mol Biol 372: 153-166.

BONNEFOY N, FOXTD (2002). Genetic transformation of Saccharomyces cerevisiae mitochondria. Methods Enzymol 350: 97-111.

BONNEFOY N, BSAT N, FOXTD (2001). Mitochondrial translation of Saccharomyces cerevisiae COX2 mRNA is controlled by the nucleotide sequence specifying the pre-Cox2p leader peptide. Mol Cell Biol 21: 2359-2372.

BOORE JL (1999). Animal mitochondrial genomes. Nucleic Acids Res 27: 1767-1780.

CARDOL P (2011). Mitochondrial NADH:ubiquinone oxidoreductase (complex I) in eukaryotes: A highly conserved subunit composition highlighted by mining of protein databases. Biochim Biophys Acta 1807: 1390-1397.

CHINNERY PF, TAYLOR RW, DIEKERT K, LILL R, TURNBULL DM, LIGHTOWLERS RN (1999). Peptide nucleic acid delivery to human mitochondria. Gene Ther 6: 1919-1928.

CHOMYNA, MEOLA G, BRESOLIN N, LAI ST, SCARLATO G, ATTARDI G (1991). In vitro genetic transfer of protein synthesis and respiration defects to mitochondria DNA-less cells with myopathy-patient mitochondria. Mol Cell Biol 11: 2236-2244.

COLLOMBET J-M, WHEELER VC, VOGEL F, COUTELLE C (1997). Introduction of plasmid DNA into isolated mitochondria by electroporation. A novel approach toward gene correction for mitochondrial disorders. J Biol Chem 272: 5342-5347.

DIMAURO S (2007). Mitochondrial DNA medicine. Biosci Rep 27: 5-9.

FLIERL A, JACKSON C, COTTRELL B, MURDOCK D, SEIBEL P, WALLACE DC (2003). Targeted delivery of DNA to the mitochondrial compartment via import sequence-conjugated peptide nucleic acid. Mol Ther 7: 550-557.

FOXTD, SANFORD JC, MCMULLIN TW (1988). Plasmids can stably transform yeast mitochondria lacking endogenous mtDNA. Proc NatlAcad SciUSA 85: 7288-7292.

GEROMEL V, CAO A, BRIANE D, VASSY J, ROTIG A, RUSTIN P, COUDERT R, RIGAUT JP, MUNNICHA, TAILLANDIER E (2001). Mitochondria transfection by 
oligonucleotides containing a signal peptide and vectorized by cationic liposomes. Antisense Nucleic Acid Drug Dev 11: 175-180.

GRAY MW (1999). Evolution of organellar genomes. Curr Opin Genet Dev 9: 678-687.

GUTIERRES S, SABAR M, LELANDAIS C, CHETRIT P, DIOLEZ P, DEGAND H, BOUTRY M, VEDEL F, DE KOUCHKOVSKY Y, DE PAEPE R (1997). Lack of mitochondrial and nuclear-encoded subunits of complex I and alteration of the respiratory chain in Nicotiana sylvestris mitochondrial deletion mutants. Proc Natl Acad Sci USA 94: 3436-3441.

HANDA H (2003). The complete nucleotide sequence and RNA editing content of the mitochondrial genome of rapeseed (Brassica napus L.): comparative analysis of the mitochondrial genomes of rapeseed and Arabidopsis Thaliana. Nucleic Acids Res 31: 5907-5916.

HAYASHI J-I, OHTA S, KIKUCHI A, TAKEMITSU M, GOTO Y-I, NONAKA I (1991). Introduction of disease-related mitochondrial DNA deletions into HeLa cells lacking mitochondrial DNA results in mitochondrial dysfunction. Proc Natl Acad Sci USA 88: 10614-10618.

HIRAMATSU T, MISUMI O, KUROIWA T, NAKAMURA S (2006). Morphological changes in mitochondrial and chloroplast nucleoids and mitochondria during the Chlamydomonas reinhardtii (Chlorophyceae) cell cycle. J Phycol 42: 1048-1058.

HU Z, FAN Z, ZHAO Z, CHEN J, LI J (2012). Stable expression of antibiotic-resistant gene ble from Streptoalloteichus hindustanus in the mitochondria of Chlamydomonas reinhardtii. PLOS ONE 7: e35542.

HU Z, ZHAO Z, WU Z, FAN Z, CHEN J, WU J, LI J (2011). Successful expression of heterologous egfp gene in the mitochondria of a photosynthetic eukaryote Chlamydomonas reinhardtii. Mitochondrion 11: 716-721.

HUANG Y, SHENOY S, LU B, LIU W, LI C (2012). Kinase signaling dysfunction in Parkinson's disease: a reverse genetic approach in Drosophila. J Neurogenet 26: 158-167.

IRWIN MH, JOHNSON LW, PINKERT CA (1999). Isolation and microinjection of somatic cell-derived mitochondria and germline heteroplasmy in transmitochondrial mice. Transgenic Res 8: 119-123.

JANSKAH, SARRIAR, WOLOSZYNSKAM, ARRIETA-MONTIELM, MACKENZIESA (1998). Stoichiometric shifts in the common bean mitochondrial genome leading to male sterility and spontaneous reversion to fertility. Plant Cell 10: 1163-1180.

JOHNSTON SA, ANZIANO PQ, SHARK K, SANFORD JC, BUTOW RA (1988). Mitochondrial transformation in yeast by bombardment with microprojectiles. Science 240: 1538-1541.

KARPOVAOV, NEWTONKJ (1999). A partially assembled complex I in NAD4-deficient mitochondria of maize. Plant $J$ 17: 511-521.

KNOOP V (2004). The mitochondrial DNA of land plants: peculiarities in phylogenetic perspective. Curr Genet 46: 123-139.

KOULINTCHENKO M, TEMPERLEYRJ, MASON PA, DIETRICHA, LIGHTOWLERS RN (2006). Natural competence of mammalian mitochondria allows the molecular investigation of mitochondrial gene expression. Hum Mol Genet 15: 143-154.

LAROSA V, COOSEMANS N, MOTTE P, BONNEFOY N, REMACLE C (2012). Reconstruction of a human mitochondrial complex I mutation in the unicellular green alga Chlamydomonas. Plant J 70: 759-768.

MAUL JE, LILLY JW, CUI L, DEPAMPHILIS CW, MILLER W, HARRIS EH, STERN DB (2002). The Chlamydomonas reinhardtiiplastid chromosome: islands of genes in a sea of repeats. Plant Cell 14: 2659-2679.

MERCHANT SS, PROCHNIK SE, VALLON O, HARRIS EH, KARPOWICZ SJ, WITMAN GB, TERRY A, SALAMOV A, FRITZ-LAYLIN LK, MARÉCHAL-DROUARD L, MARSHALL WF, QU L-H, NELSON DR, SANDERFOOT AA, SPALDING MH, KAPITONOV VV, REN Q, FERRIS P, LINDQUIST E, SHAPIRO H, LUCAS SM, GRIMWOOD J, SCHMUTZ J, CHLAMYDOMONAS ANNOTATION TEAM, JGI ANNOTATION TEAM, GRIGORIEV IG, ROKHSAR DS, GROSSMAN AR (2007). The Chlamydomonas genome reveals the evolution of key animal and plant functions. Science 318: 245-251.

PETERSEN KF, BEFROY D, DUFOUR S, DZIURA J, ARIYAN C, ROTHMAN DL, DIPIETRO L, CLINE GW, SHULMAN GI (2003). Mitochondrial dysfunction in the elderly: possible role in insulin resistance. Science 300: 1140-1142.

RAHRMANN EP, WATSON AL, KENG VW, CHOI K, MORIARITY BS, BECKMANN DA, WOLF NK, SARVER A, COLLINS MH, MOERTEL CL, WALLACE MR, GEL B, SERRA E, RATNER N, LARGAESPADA DA (2013). Forward genetic screen for malignant peripheral nerve sheath tumor formation identifies new genes and pathways driving tumorigenesis. Nat Genet: in press (doi: 10.1038/ng:2641).
RANDOLPH-ANDERSON BL, BOYNTON JE, GILLHAM NW, HARRIS EH, JOHNSON AM, DORTHU M-P, MATAGNE RF (1993). Further characterization of the respiratory deficient dum-1 mutation of Chlamydomonas reinhardtii and its use as a recipient for mitochondrial transformation. Mol Gen Genet 236: 235-244.

REMACLE C, CARDOLP, COOSEMANS N, GAISNE M, BONNEFOYN (2006). Highefficiency biolistic transformation of Chlamydomonas mitochondria can be used to insert mutations in complex I genes. Proc Natl Acad Sci USA 103: 4771-4776.

REMACLE C, DUBY F, CARDOL P, MATAGNE RF (2001). Mutations inactivating mitochondrial genes in Chlamydomonas reinhardtii. Biochem Soc Trans 29:442-446.

REMACLE C, LAROSA V, SALINAS T, HAMEL P, SUBRAHMANIAN N, BONNEFOY N, KEMPKEN F (2012). Transformation and nucleic acid delivery to mitochondria. In Genomics of Chloroplast and Mitochondria, Advances in Photosynthesis and Respiration, Vol. 35 (Eds R Bock and V Knoop). Springer, Dordrecht, pp. 443-458.

SALINAS T, DUBY F, LAROSA V, COOSEMANS N, BONNEFOY N, MOTTE P, MARÉCHAL-DROUARD L, REMACLE C (2012). Co-evolution of mitochondrial tRNA import and codon usage determines translational efficiency in the green alga Chlamydomonas. PLoS Genet 8: e1002946.

SEIBEL P, TRAPPE J, VILLANI G, KLOPSTOCK T, PAPA S, REICHMANN H (1995). Transfection of mitochondria: strategy towards a gene therapy of mitochondrial DNA diseases. Nucleic Acids Res 23: 10-17.

SLOANDB, ALVERSONAJ, CHUCKALOVCAKJP, WU M, MCCAULEYDE, PALMER JD, TAYLOR DR (2012). Rapid evolution of enormous, multichromosomal genomes in flowering plant mitochondria with exceptionally high mutation rates. PLoS Biol 10: e1001241.

SMALL ID, ISAAC PG, LEAVER CJ (1987). Stoichiometric differences in DNA molecules containing the atpA gene suggest mechanisms for the generation of mitochondrial genome diversity in maize. EMBO J 6: 865-869.

STEELE DF, BUTLER CA, FOX TD (1996). Expression of a recoded nuclear gene inserted into yeast mitochondrial DNA is limited by mRNA-specific translational activation. Proc Natl Acad Sci USA 93: 5253-5257.

TAKEDA K, TASAI M, IWAMOTO M, ONISHI A, TAGAMI T, NIRASAWA K, HANADA $\mathrm{H}$, PINKERT CA (2005). Microinjection of cytoplasm or mitochondria derived from somatic cells affects parthenogenetic development of murine oocytes. Biol Reprod 72: 1397-4104.

TAYLORRW, TURNBULLDM (2005). Mitochondrial DNAmutations in human disease. Nat Rev Genet 6: 389-402.

TERASAWA K, ODAHARA M, KABEYA Y, KIKUGAWA T, SEKINE Y, FUJIWARA M, SATO N (2007). The mitochondrial genome of the moss Physcomitrella patens sheds new light on mitochondrial evolution in land plants. Mol Biol Evol24:699-709.

TORRES-BACETE J, NAKAMARU-OGISO E, MATSUNO-YAGI A, YAGI T (2007). Characterization of the NuoM (ND4) subunit in Escherichia coli NDH-1. Conserved charged residues essential for energy-coupled activities. J Biol Chem 282: 36914-36922.

TRIFUNOVIC A, WREDENBERG A, FALKENBERG M, SPELBRINK JN, ROVIO AT, BRUDER CE, BOHLOOLY-Y M, GIDLÖF S, OLDFORS A, WIBOM R, TÖRNELL J, JACOBS HT, LARSSON N-G (2004). Premature ageing in mice expressing defective mitochondrial DNA polymerase. Nature 429: 417-423.

UNSELD M, MARIENFELD JR, BRANDTP, BRENNICKEA(1997). The mitochondrial genome of Arabidopsis Thaliana contains 57 genes in 366,924 nucleotides. Nat Genet 15: 57-61.

VAHRENHOLZ C, RIEMEN G, PRATJE E, DUJON B, MICHAELIS G (1993). Mitochondrial DNA of Chlamydomonas reinhardtii: the structure of the ends of the linear 15.8-kb genome suggests mechanisms for DNA replication. Curr Genet 24: $241-247$.

VALR, WYSZKO E, VALENTIN C, SZYMANSKI M, COSSETA, ALIOUAM, DREHER TW, BARCISZEWSKIJ, DIETRICHA(2011). Organelle trafficking of chimeric ribozymes and genetic manipulation of mitochondria. NucleicAcids Res 39:9262-9274.

VESTWEBERD, SCHATZG (1989). DNA-protein conjugates can enter mitochondria via the protein import pathway. Nature 338: 170-172.

VINOGRADOVAE, SALINAS T, COGNAT V, REMACLE C, MARÉCHAL-DROUARD $\mathrm{L}$ (2009). Steady-state levels of imported tRNAs in Chlamydomonas mitochondria are correlated with both cytosolic and mitochondrial codon usages. Nucleic Acids Res 37: 1521-1518.

WARD BL, ANDERSON RS, BENDICHAJ (1981). The mitochondrial genome is large and variable in a family of plants (Cucurbitaceae). Cell 25: 793-803.

WOLOSZYNSKA M (2010). Heteroplasmy and stoichiometric complexity of plant 
mitochondrial genomes--though this be madness, yet there's method in't. J Exp Bot 61: 657-671.

YAMASKI T, KUROKAWA S, WATANABE KI, IKUTA K, OHAMA T (2005). Shared molecular characteristics of successfully transformed mitochondrial genomes in Chlamydomonas reinhardtii. Plant Mol Biol 58: 515-527.

YOON YG, KOOB MD (2005) Transformation of isolated mammalian mitochondria by bacterial conjugation. Nucleic Acids Res 33: e139.

YUH, KOILKONDARD, CHOU T-H, PORCIATTI V, OZDEMIR SS, CHIODO V, BOYE
SL, BOYE SE, HAUSWIRTH WW, LEWIN AS, GUY J (2012a). Gene delivery to mitochondria by targeting modified adenoassociated virus suppresses Leber's hereditary optic neuropathy in a mouse model. Proc Natl Acad Sci USA 109 E1238-E1247.

YU H, OZDEMIR SS, KOILKONDARD, CHOU T-H, PORCIATTI V, CHIODO V, BOYE SL, HAUSWIRTH WW, LEWIN AS, GUY J (2012b). Mutant NADH dehydrogenase subunit 4 gene delivery to mitochondria by targeting sequence-modified adeno-associated virus induces visual loss and optic atrophy in mice. Mol Vis 18: $1668-1683$.

\section{Further Related Reading, published previously in the Int. J. Dev. Biol.}

Role of mitochondrial DNA replication during differentiation of reprogrammed stem cells Richard D.W. Kelly and Justin C. St. John Int. J. Dev. Biol. 54: 1659 - 1670 (2010) http://dx.doi.org/10.1387/ijdb.103202rk

\begin{abstract}
Expression of paternal and maternal mitochondrial HSP70 family, hsc74, in preimplantation mouse embryos

P Dvorak, D Dvorakova, A Yoshiki, T Ohashi, K Kitamura and M Kusakabe Int. J. Dev. Biol. 39: 511 - 517 (1995)
\end{abstract}

Plastids unleashed: their development and their integration in plant development Enrique Lopez-Juez and Kevin A. Pyke Int. J. Dev. Biol. (2005) 49: 557-577 http://dx.doi.org/10.1387/ijdb.051997el

\section{Regulation of gene expression by light} Jorge J. Casal and Marcelo J. Yanovsky Int. J. Dev. Biol. (2005) 49: 501-511 http://dx.doi.org/10.1387/ijdb.051973jc

Plant protoplasts as genetic tool: selectable markers for developmental studies I Negrutiu, S Hinnisdaels, D Cammaerts, W Cherdshewasart, G Gharti-Chhetri and M Jacobs Int. J. Dev. Biol. (1992) 36: 73-84

5 yr ISI Impact Factor $(2011)=2.959$
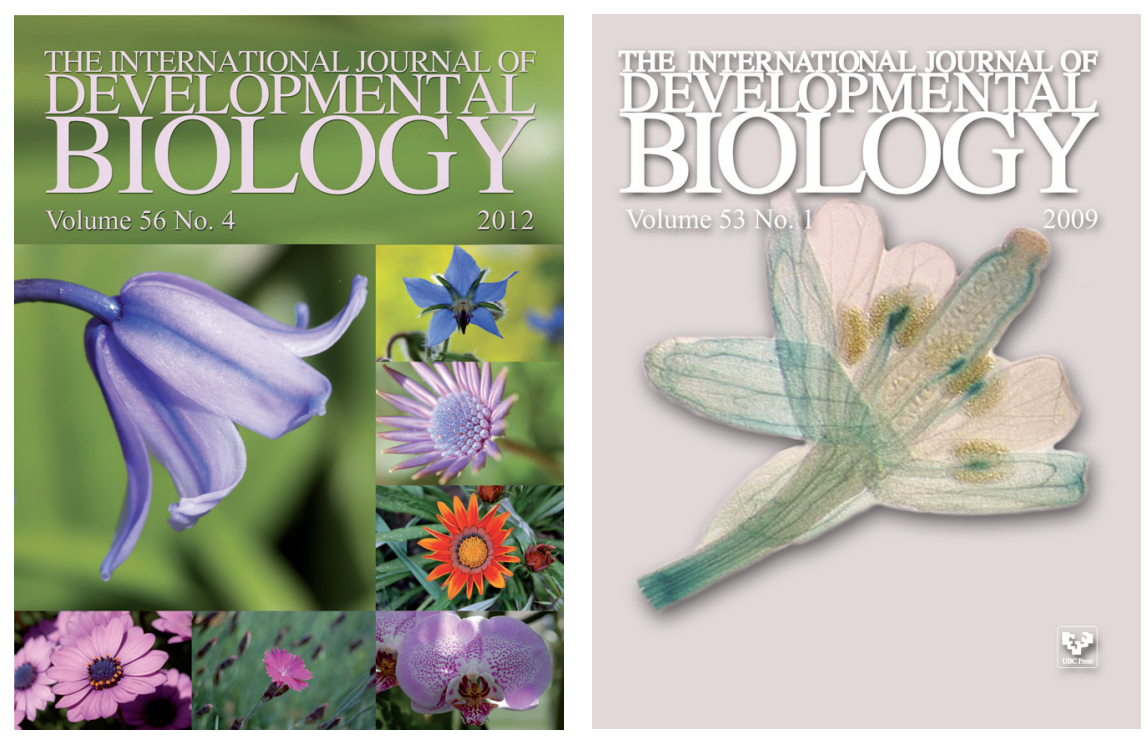

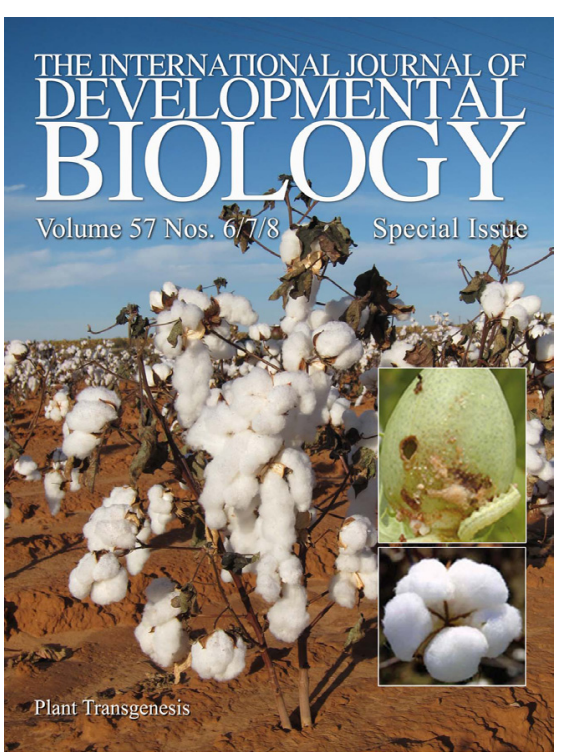

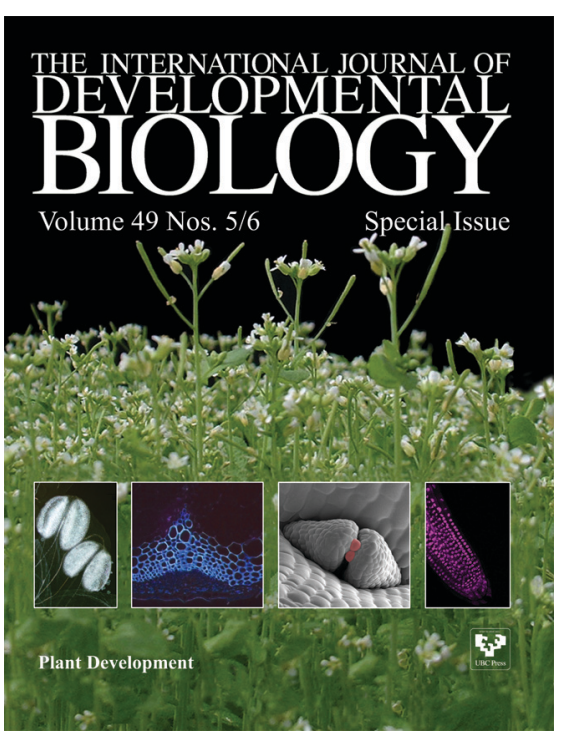

